\title{
Rogg, Matthias, Armee des Volkes ? Militär und Gesellschaft in der DDR
}

\section{Emmanuel Droit}

\section{OpenEdition}

Journals

Édition électronique

URL : http://journals.openedition.org/ifha/6703

DOI : $10.4000 /$ ifha. 6703

ISSN : 2198-8943

Éditeur

IFRA - Institut franco-allemand (sciences historiques et sociales)

Référence électronique

Emmanuel Droit, « Rogg, Matthias, Armee des Volkes ? Militär und Gesellschaft in der DDR », Revue de I'IFHA [En ligne], Date de recension, mis en ligne le 01 janvier 2011, consulté le 22 septembre 2020. URL : http://journals.openedition.org/ifha/6703 ; DOI : https://doi.org/10.4000/ifha.6703

Ce document a été généré automatiquement le 22 septembre 2020

(CIFHA 


\title{
Rogg, Matthias, Armee des Volkes? Militär und Gesellschaft in der DDR
}

\author{
Emmanuel Droit
}

1 À rebours d'une histoire militaire traditionnelle de la RDA, centrée depuis l'ouverture des archives au début des années 1990 sur les origines et les structures de l'armée, l'historien (et soldat de métier !) M.R. entreprend d'étudier de façon minutieuse les liens entre l'Armée Nationale du Peuple (NVA) et la société est-allemande. À partir d'un corpus riche et varié de sources écrites, orales, iconographiques et audiovisuelles, il démontre comment cette institution fonctionne comme un instrument de disciplinarisation. En ce sens, M.R. s'inscrit dans un courant historiographique porté par des historiens comme Thomas Lindenberger et mû par l'ambition d'écrire une histoire sociale de la domination politique.

2 Le livre est constitué de huit chapitres thématiques, mais le choix de cette architecture conduit à masquer des évolutions, notamment le passage de l'utopie prométhéenne de la «personnalité socialiste du soldat » à la gestion parfois problématique des « soldats de demain » (pour cause d'alcoolisme, de manque de motivation).

3 L'historien allemand nous invite tout d'abord à une histoire des représentations au sein de la NVA marquée par une culture binaire de guerre froide qui séparait le monde entre amis et ennemis. M.R. se livre ensuite à une analyse des structures de mobilisation mises en place par l'armée et destinées d'une part à diffuser les valeurs militaires au sein de la société est-allemande et d'autre part à recruter de futurs officiers et sousofficiers parmi la jeunesse. L'historien allemand s'intéresse notamment au rôle éducatif de l'armée et de ses organisations paramilitaires, telle la Société pour le sport et la technique (GST). Il présente de façon complète le répertoire d'actions mobilisé par la NVA dans les champs de l'école et de l'entreprise.

4 Les chapitres suivants sont réellement novateurs dans la mesure où l'auteur cherche à entrer à l'intérieur de l'armée. Il développe une approche anthropologique très intéressante, étudiant tour à tour le monde de la caserne et de la "société militaire " (femmes, enfants, vie familiale). M.R. conclut à une « relation aseptique » (p. 447) entre l'armée et la société civile car la NVA fonctionnait en monde clos. Toutefois, ce manque 
d'interactions était ponctuellement comblé à l'occasion de mobilisations pour des récoltes agricoles, l'extraction du lignite ou la participation à des grands chantiers de prestige du SED comme le Palais de la République. L'historien allemand déconstruit très finement l'image des « soldats des champs et des fabriques » qui étaient finalement là pour compenser le manque de main d'œuvre. Il fait ensuite un détour par l'étude des soldats réservistes et des retraités de l'armée pour qui le retour à la vie civile était parfois difficile. Le livre se termine par une analyse des motivations et de l'attitude des appelés à partir des enquêtes statistiques produites par le régime entre les années 1960 et 1980 . Sans surprise, M.R. souligne le mécontentement croissant des soldats, ce qui expliquerait selon l'auteur le fait que le SED ait renoncé à faire appel à l'armée pour écraser la " révolution pacifique ».

5 En dépit de l'absence d'une étude sociologique et prosopographique des militaires, de la réception du socialisme militarisé au sein de la société, tout le mérite de cette étude est de montrer que la NVA était moins une armée du peuple et davantage une armée au service du Parti.

Emmanuel Droit (université Rennes II, CERHIO) 